\title{
Evaluation of Turner Syndrome Knowledge among Physicians and Parents
}

\author{
(D) Berna Eroğlu Filibeli ${ }^{1}$, (D) Nesrin Havare2 ${ }^{2}$ (D) Huriye Erbak Yılmaz³, (D) Jülide Gülizar Yıldırım4, (D) Gönül Çatlı5, (D) Bumin N. Dündar5 \\ 1 University of Health Sciences Turkey, Tepecik Training and Research Hospital, Clinic of Pediatric Endocrinology, Izmir, Turkey \\ 2 University of Health Sciences Turkey, Tepecik Training and Research Hospital, Clinic of Pediatrics, Izmir, Turkey \\ ${ }^{3}$ Katip Çelebi University, Atatürk Traning and Research Hospital, Clinic of Biochemistry, Izmir, Turkey \\ ${ }^{4}$ Katip Çelebi University Faculty of Health Sciences, Department of Public Health Nursing, Izmir, Turkey \\ ${ }^{5}$ Katip Çelebi University Faculty of Medicine, Department of Pediatric Endocrinology, Izmir, Turkey
}

\begin{abstract}
What is already known on this topic?
Turner syndrome (TS) is one of the most commonly observed chromosomal abnormalities, estimated at around 1 in 2500 live births. To the best of our knowledge, there are no studies related to the incidence of TS in Turkey. Nevertheless, in a multicenter study carried out in 2013-2014, 842 patients with TS between 0-18 ages were examined retrospectively in 35 different centers, and the average diagnosis age was determined as $10.2 \pm 4.4$ years. It is thought that TS is diagnosed at a later age in Turkey.
\end{abstract}

\section{What this study adds?}

This study shows that physicians do not have adequate knowledge of TS. Poor knowledge about TS may increase diagnosis delays. The education program about TS should be revised and implemented to address this problem at the medical faculty and post-graduate levels.

\section{Abstract}

Objective: Turner syndrome (TS) is one of the most common chromosomal abnormalities and an important cause of short stature and infertility due to ovarian failure in females. The aim was to evaluate the knowledge of TS among physicians and parents of children with TS and to enhance awareness about this subject.

Methods: One hundred and forty physicians were included in the study. The study population comprised 37 pediatricians (26.4\%), 15 gynecologists $(10.7 \%), 88$ family physicians $(62.9 \%)$ and 30 parents who had daughters with a diagnosis of TS. Two separate questionnaires were administered to evaluate TS knowledge of physicians and parents.

Results: According to the self-reports of physicians, $49 \%$ had insufficient knowledge of TS, while $15.7 \%$ indicated that they had no knowledge of TS. The mean percentage of correct answers was $50.71 \pm 16.17 \%$ for all physicians. When the entire group of physicians was considered, $67.1 \%$ of them did not know the approximate incidence of TS, while $14.3 \%$ of them incorrectly indicated that TS was a condition that was seen in boys. The mean percentage of correct answers among parents was $68 \pm 15 \%$, and there was no difference between the mothers' and fathers' correct answer rates $(p=0.063)$. The majority of parents was not aware of TS-associated diseases and increased malignancy risk in TS.

Conclusion: Physician knowledge of TS was poor and that there is a need for continued education about TS at the medical faculty and post-graduate levels.

Keywords: Turner syndrome, knowledge levels, questionnaire, education 


\section{Introduction}

Turner syndrome (TS) is a sex chromosome abnormality in females, characterized by partial or complete loss of one of the X chromosomes (1). In nearly half of patients, it can be diagnosed in infancy with the presence of typical clinical findings. While a limited number of patients with TS are diagnosed with short stature during childhood, the rest of them are diagnosed with primary amenorrhea in adolescence (2). Through early diagnosis and appropriate treatment of these patients (growth hormone treatment, estrogen replacement, training and psychological support), they have a chance to participate in academic and social life, and they also achieve nearly normal adult height, bone density and sexual development. Several studies have focused on diagnosing TS earlier $(3,4,5)$. Chronic complications may be prevented by earlier diagnosis and initiating treatment at birth or during infancy. Additionally, parents can deal with the situation more easily with early TS diagnosis (6).

Although TS is common, the exact incidence of TS in Turkey is unknown, and awareness regarding this issue may be inadequate. Patients with TS are diagnosed late in Turkey. Therefore, in this study, we aimed to evaluate the TS knowledge and awareness levels of physicians and parents of children with TS.

\section{Methods}

This descriptive study was a questionnaire survey. The researchers designed two questionnaires; one to be administered to physicians volunteers $(n=140)$ and the other to parents $(n=30)$. The questionnaire for the physicians was developed based on the current literature, guidelines, and expert opinions $(7,8)$. The questionnaire for the parents was developed based on family information flyers from the internet and expert opinions (TS: a guide for families https://turnersyndromefoundation.org/wpcontent/uploads/2017/08/New-Turner-Syndrome-Guide-forFamilies-Patricia-Reiser-CFNP-and-Marsha-Davenport-MD. pdf and http://nhfv.org/wp-content/uploads/2016/02/TurnerSyndrome-A-Guide-for-Families.pdf). This study included pediatricians, gynecologists, family physicians and parents whose children were diagnosed with TS. Ethics committee approval for the surveys was obtained from the Katip Çelebi University Local Ethics Committee (date: 16 June 2016, ethics approval number: 194). The physicians and parents in question were informed about the questionnaire, and surveys were performed face-to-face by NK after the informed consent form had been signed. An attempt was made to word all questions in a neutral manner. All response data of the participants were analyzed anonymously. No incentives were provided to the respondents.

The first physician survey comprised 18 multiple-choice questions. The first four questions assessed the physicians' specialties, proficiency regarding TS knowledge, number of years working in their profession and the institutions that they work for. The other 14 questions included TS epidemiology, clinical findings, diagnosis, treatment and follow-up recommendations. There were 19 "yes/no" questions in the survey designed for the parents. The first few questions concerned the demographic features (age, gender and education status) of the parent, and the remaining questions concerned the diagnosis, treatment and followup of TS. The patients' age at diagnosis was obtained from medical records. The answers were evaluated as correct or incorrect by researchers. Examples of the questionnaires applied to both physicians and parents are given in the supplementary documents (Supplementary 1,2).

\section{Statistical Analysis}

The sample size was calculated according to the estimated size within the sampling universe using the formula referred to as 'the formula to estimate the number of individuals for a known sample and width of population' (9).

The analysis of physician survey data was carried out using Statistical Package for the Social Sciences, version 22.0, program (IBM Inc., Armonk, NY, USA), and the percentage distribution was performed using the chi-square test. Descriptive statistics for family surveys, however, were presented as frequency, percentage, average, standard deviation, median, minimum, maximum and range values. In the analysis of differences between measurement values of the two groups, the Mann-Whitney U test or the independent sample t-test were used according to the distribution. A significance test for the difference in two proportions and a Pearson chi-square test were used. A $p<0.05$ was considered statistically significant.

\section{Results}

A total of 140 physicians working at training and research hospitals, state hospitals, university hospitals and primary care clinics (PCCs) and 30 parents whose children had been diagnosed with TS were included in the study. Of the physicians, $62.9 \%$ were family physicians, $26.4 \%$ were pediatricians and $10.7 \%$ were gynecologists. A total of $50.7 \%$ of physicians were working at training and research hospitals, $15 \%$ at universities, $3.6 \%$ at state hospitals and $30.7 \%$ at PCCs and $62.9 \%$ of them had been working for 10 years or less. 


\section{Physician Knowledge of Turner Syndrome}

Thirty-five percent of physicians self-reported that their knowledge level of TS was adequate, $49.3 \%$ indicated that their knowledge was insufficient and $15.7 \%$ reported having no knowledge of TS. When all the physicians were considered, the rate of correct answers was $50.71 \pm 16.17 \%$. The percentages of correct answers among the 88 family physicians, 37 pediatricians and 15 gynecologists were $46.08 \pm 16.51,56.2 \pm 19.02$ and $58.3 \pm 20.4$, respectively.

Responses to several questions related to the frequency and findings of TS are presented in Table 1. For the question concerning chromosomal abnormality, the pediatricians' accurate answer rate was higher than that of other specialties $(p=0.023)$. The question that referred to the type of hypogonadism was answered incorrectly by $72.1 \%$ of all physicians; however, $53.3 \%$ of gynecologists answered it correctly.

Gynecologists had the highest accurate answer rate related to fertility and malignancy questions ( $p=0.028) ; 64.3 \%$ of physicians mistakenly thought that the intelligence level of patients with TS was low. Pediatricians were significantly more well-informed regarding this issue $(p=0.018)$. Approximately $63.6 \%$ of the physicians gave incorrect answers to the question regarding estrogen and growth hormone treatment (Table 2).

\section{Knowledge of Parents About Turner Syndrome}

Thirty parents whose children were diagnosed with TS participated in the study. The mean age of girls with TS was $58.8 \pm 50.95$ months. The median diagnostic age was 66 months (1-168 months). The parents' percentage of correct answers was $68 \pm 15 \%$, and no significant difference was found between mothers and fathers (mothers $74 \%$, fathers $63 \% ; p=0.063$ ). The rate of correct responses among parents was higher than that of physicians, but the difference was not significant. Parent responses to several questions regarding TS are presented in Table 3.

The median correct response rate of primary school graduates was $74 \%$ (range, 37-84\%), and the median correct response rate of high school or university graduates was $66 \%$ (range, 32-89\%). There was no significant difference between the parents according to their educational status $(p=0.690)$. However, the median (range) age at diagnosis was significantly younger in children of parents who graduated from high school [21 months (1-120) vs. 90 months (1-168); $p=0.008$.

Table 1. Numbers and percentages of item responses on the survey of physician knowledge about Turner syndrome frequency and findings

\begin{tabular}{|c|c|c|c|c|}
\hline & \multicolumn{3}{|c|}{ Number of correct answers (\%) } & \multirow[t]{2}{*}{$\mathrm{p}$} \\
\hline & $\begin{array}{l}\text { Gynecologists } \\
(n=15)\end{array}$ & $\begin{array}{l}\text { Pediatricians } \\
(\mathrm{n}=37)\end{array}$ & $\begin{array}{l}\text { Family physicians } \\
(\mathrm{n}=88)\end{array}$ & \\
\hline Frequency & $6(40 \%)$ & $15(40.5 \%)$ & $25(28.4 \%)$ & 0.345 \\
\hline Gender & $12(80 \%)$ & $31(83.3 \%)$ & $77(87.5 \%)$ & 0.690 \\
\hline Chromosomal abnormality & $13(86.7 \%)$ & $35(94.6 \%)$ & $65(73.9 \%)$ & 0.023 \\
\hline Hypergonadotropic or hypogonadotropic hypogonadism & $8(53.3 \%)$ & $12(32.4 \%)$ & $19(21.6 \%)$ & 0.031 \\
\hline Physical examination findings & $9(60 \%)$ & $23(62.2 \%)$ & $33(37.5 \%)$ & 0.022 \\
\hline Most common finding: short stature & $9(60 \%)$ & $26(70.3 \%)$ & $43(48.9 \%)$ & 0.084 \\
\hline
\end{tabular}

Table 2. Number and percentages of the item responses on the survey of physician knowledge about diseases associated with Turner syndrome

\begin{tabular}{|c|c|c|c|c|}
\hline & \multicolumn{3}{|c|}{ Number of right answers (\%) } & \multirow[t]{2}{*}{$\mathrm{p}$} \\
\hline & $\begin{array}{l}\text { Gynecologists } \\
(\mathrm{n}=15)\end{array}$ & $\begin{array}{l}\text { Pediatricians } \\
(\mathrm{n}=37)\end{array}$ & $\begin{array}{l}\text { Family physicians } \\
(\mathrm{n}=88)\end{array}$ & \\
\hline The most common cardiovascular disease & $6(40 \%)$ & $21(56.8 \%)$ & $31(35.2 \%)$ & 0.083 \\
\hline Fertility & $10(66.7 \%)$ & $10(27 \%)$ & $33(37.5 \%)$ & 0.028 \\
\hline Intelligence level & $3(20 \%)$ & $20(54.1 \%)$ & $27(30.7 \%)$ & 0.018 \\
\hline TS and malignancy & $10(66.7 \%)$ & $14(37.8 \%)$ & $27(30.7 \%)$ & 0.027 \\
\hline TS and osteoporosis coexistence & $13(86.7 \%)$ & $23(62.2 \%)$ & $56(63.6 \%)$ & 0.192 \\
\hline Definitive diagnosis & $12(80 \%)$ & $33(89.2 \%)$ & $70(79.5 \%)$ & 0.427 \\
\hline SHOX gene mutation & $5(33.3 \%)$ & $15(40.5 \%)$ & $25(28.4 \%)$ & 0.413 \\
\hline Estrogen and growth hormone treatment & $6(40 \%)$ & $12(32.4 \%)$ & $33(37.5 \%)$ & 0.826 \\
\hline
\end{tabular}


Table 3. Number and percentages of the item responses on the survey of parent knowledge about Turner syndrome

\begin{tabular}{|c|c|c|c|}
\hline & $\begin{array}{l}\text { Mother's correct answers } \\
\mathrm{n}(\%)\end{array}$ & $\begin{array}{l}\text { Father's correct answers } \\
\mathrm{n}(\%)\end{array}$ & $\mathrm{p}$ \\
\hline Genetic disorder & $16(94.1 \%)$ & $11(84.6 \%)$ & 0.565 \\
\hline Only girls are affected & $14(82.4 \%)$ & $9(69.2 \%)$ & 0.666 \\
\hline Prenatal diagnosis possibility & $12(70.6 \%)$ & $8(61.5 \%)$ & 0.705 \\
\hline The most common finding & $13(76.5 \%)$ & $11(84.6 \%)$ & 0.672 \\
\hline Chromosome abnormality & $14(82.4 \%)$ & $11(84.6 \%)$ & 1.0 \\
\hline Pregnancy probability & $14(82.4 \%)$ & $7(53.8 \%)$ & 0.123 \\
\hline Normal intelligence & $13(76.5 \%)$ & $10(76.9 \%)$ & 1.0 \\
\hline Congenital heart disease possibility & $11(64.7 \%)$ & $7(53.8 \%)$ & 0.821 \\
\hline Definitive treatment & $9(52.9 \%)$ & $4(30.8 \%)$ & 0.399 \\
\hline Short stature can be treated with growth hormone treatment & $13(76.5 \%)$ & $9(69.2 \%)$ & 0.698 \\
\hline Risk of cancer & $5(29.4 \%)$ & $2(15.4 \%)$ & 0.427 \\
\hline Risks of diabetes mellitus, thyroid and celiac disease & $8(47.1 \%)$ & $4(30.8 \%)$ & 0.465 \\
\hline Growth hormone treatment can prevent infertility & $12(70.6 \%)$ & $5(38.5 \%)$ & 0.165 \\
\hline Estrogen treatment can prevent osteoporosis & $11(64.7 \%)$ & $9(69.2 \%)$ & 1.0 \\
\hline Radiological evaluation for renal disease is necessary & $14(82.4 \%)$ & $8(61.5 \%)$ & 0.242 \\
\hline Psychiatric evaluation is required & $14(82.4 \%)$ & $9(69.2 \%)$ & 0.66 \\
\hline Clinic follow up is important & $14(82.4 \%)$ & $8(61.5 \%)$ & 0.242 \\
\hline
\end{tabular}

\section{Discussion}

TS is one of the most commonly observed chromosomal abnormalities with an incidence of 1 in 2500 live births and effects nearly 1.5 million women in the world $(2,10,11)$. There are no studies related to the incidence of TS in Turkey. Nevertheless, in a multicenter study carried out in 2013-2014, 842 patients with TS between 0-18 ages were examined retrospectively in 35 different centers, and the average diagnosis age was determined as $10.2 \pm 4.4$ years (12). In a study carried out in England, it was estimated that there were 12,500 TS cases; however, it is known that there are approximately 1000 cases in TS support associations and expert hospital clinics. This means that a large number of cases cannot be diagnosed and do not receive medical care (13). Compared to developed countries, it is thought that TS is diagnosed at a later age in Turkey. This is most likely due to the lower awareness level of Turkish physicians. For this reason, we aimed to investigate TS knowledge and awareness levels of physicians and parents whose children were diagnosed with TS. In the survey, only just over half $(50.71 \pm 16.17 \%)$ of all questions were correctly answered by physicians. It is not possible to compare our results with previous ones because, to the best of our knowledge, no study on this topic has been published in the past in Turkey or in other countries.

The question related to short stature, the most common finding in TS, was not answered properly by $51.1 \%$ of family doctors and $29.7 \%$ of pediatricians. The growth curve and monitoring of children are important in primary care. The reason for the insufficient knowledge level of physicians may be that they do not encounter such patients because there is no referral chain system. When there is no referral chain, it is difficult for family physicians to maintain health care services, and this situation forms the weakest point of the family medicine practice. In the study by Kringos (14), this situation was given as one of the most important factors why Turkey ranks in the poor category for primary care health services. The final adult height of TS patients is positively related to a younger age at diagnosis and the duration of growth hormone treatment (15). Primary care physicians missing short stature will result in late diagnosis and insufficient benefit from growth hormone treatment for all children who would have benefitted, including girls with TS. When physicians are asked about the intelligence level of children with TS, $64.3 \%$ of them answered incorrectly. The inadequate knowledge level of physicians about this issue can cause children diagnosed with TS to be guided in a wrong way and perhaps lead to their exclusion from society. Although patients with TS tend to have some problems with mathematics, these can be overcome with additional time and adequate education. The overall education level of women with TS is equal to or better than that of the overall female population (16). When educational and psychological support is commenced early in TS, it can help academic success and social integration. 
The question about high gonadotropin levels in TS was answered more correctly by gynecologists, compared to the physicians in other specialties. This shows that undiagnosed and late-diagnosed girls sought the care of gynecologists with a primary amenorrhea complaint. Although family physicians and pediatricians had inadequate knowledge regarding fertility, $66.7 \%$ of gynecologists answered the question correctly. This could be explained by the fact that patients diagnosed with TS consult them for infertility treatment. Most women with TS will be infertile; however, pregnancy has been achieved with oocyte donation and in vitro fertilization (17).

Today, many diseases can be diagnosed with simple scanning programs, and in this way, more significant complications can be prevented. The standard approach for cardiac evaluation in TS is echocardiography and four extremity blood pressure measurements that should be performed on every patient at the time of diagnosis $(18,19)$. Even if echocardiography is normal, every patient should be evaluated with magnetic resonance imaging as soon as it is feasible without the need for general anesthesia $(7,20)$. Physicians responded to the question related to cardiovascular disease incorrectly $58.6 \%$ of the time. A lack of knowledge can cause late-diagnosed cardiovascular system diseases and increased mortality. There is an increased risk of gonadoblastoma in patients with TS carrying $\mathrm{Y}$ chromosome fragmentation, and it is known that remocal of streak gonads are performed by obstetricians and gynecologists. It was not surprising that gynecologists were more knowledgeable than other physicians in terms of the combination of TS and malignancy.

The TS knowledge level of physicians was determined to be unsatisfactory when compared with the knowledge of TS parents. As families research TS in a detailed way after diagnosis, it is not wrong to expect their knowledge level to be higher. Parents want to obtain all information related to the disease since TS is an unknown disease in society and therefore there is an increased level of concern in families. Parents responded with $90 \%$ correct answers to the question about TS being a genetic disease. We can imply that this chronic condition led to desperation in families, which increased their solution-oriented quests. Nevertheless, parent knowledge was not sufficient in relation to the diseases accompanying TS and parents should be informed by specialists about this. In a study performed on children with chronic disease, it was reported that there was an important effect of the relationship between the families of hospitalized children and the nurses conducting the care of the sick children. However, the physicians were not well informed about the problems regarding psychosocial adjustment $(21,22)$. Meeting the psychosocial and educational requirements, as well as the medical requirements, of the population affected by chronic disease will increase the childrens' and families' quality of life in both the acute and follow-up periods. Additionally, it will positively affect communication between health personnel and families.

The awareness level of primary care family physicians, pediatricians and gynecologists should be enhanced in the areas of early diagnosis and treatment to decrease mortality and morbidity in patients with TS. Our study has revealed troubles related to this issue. It has been shown that major social campaigns are effective in the renewal of knowledge for both families with sick children and physicians, and there is an apparent increase in the early diagnosis of diseases (16). Education programs must be regularly applied to staff by experts in issues such as the requirements of ill children and their parents, and all staff members must be offered counselling services in healthcare organizations. Qualified staff must be employed to apply psychological support, social orientation, and special programs for sick children and their families in healthcare organizations. Therefore, the results show that education programs should be maintained following graduation as well. New early diagnosis strategies should be developed to overcome the delay of treatment in patients with TS.

\section{Study Limitations}

The limitation of this study is the relatively small number of physicians and parents of girls with TS. Accordingly, generalizations from these findings to the total population of physicians and families with children diagnosed with TS must be made cautiously.

\section{Conclusion}

This study indicates that the knowledge about TS of physicians (especially family physicians) was insufficient, although TS is a relatively common disease. To prevent late diagnosis, increased complications and inadequate treatment in patients with TS, post-graduation education programs for physicians should be increased, and the referral chain of the patient must be applied in the health system. The parents' answers showed that they were worried about TS and the associated problems (short stature, infertility, etc.) and they sought information about TS from clinicians, brochures and the internet. Intermittent information and training programs should be organized for families with TS. Cooperation between the physicians and parents provides 
better follow-up for these children and better control of the accompanying conditions related to TS.

\section{Ethics}

Ethics Committee Approval: The study protocol was approved by the Katip Çelebi University Ethical Committee (approved number: 16/06/2016-194).

Informed Consent: The physicians and parents in question were informed about the questionnaire, and surveys were performed face-to-face by NK after the informed consent form had been signed.

Peer-review: Externally and internally peer-reviewed.

\section{Authorship Contributions}

Medical Practices: Berna Eroğlu Filibeli, Nesrin Havare, Huriye Erbak Yılmaz, Gönül Çatlı, Bumin N. Dündar, Concept: Bumin N. Dündar, Design: Bumin N. Dündar, Data Collection or Processing: Nesrin Havare, Huriye Erbak Yilmaz, Jülide Gülizar Yıldırım, Analysis or Interpretation: Jülide Gülizar Yıldırım, Berna Eroğlu Filibeli, Gönül Çatlı, Bumin N. Dündar, Literature Search: Berna Eroğlu Filibeli, Nesrin Havare, Gönül Çatlı, Bumin N. Dündar, Writing: Berna Eroğlu Filibeli, Nesrin Havare, Gönül Çatlı, Bumin N. Dündar.

Financial Disclosure: The authors declared that this study received no financial support.

\section{References}

1. Turner HH. A syndrome of infantilism, congenital webbed neck, and cubitus valgus. Endocrinology 1938;23:566-574.

2. Elsheikh M, Dunger DB, Conway GS, Wass JA. Turner's syndrome in adulthood. Endocr Rev 2002;23:120-140.

3. Gravholt $\mathrm{CH}$. Medical problems of adult Turner's syndrome. Horm Res 2001;56(Suppl 1):44-50.

4. Rivkees SA. Ending the late diagnosis of Turner syndrome through a novel high-throughput assay. Pediatr Endocrinol Rev 2012;9(Suppl 2):698-700

5. Apperley L, Das U, Ramakrishnan R, Dharmaraj P, Blair J, Didi M, Senniappan S. Mode of clinical presentation and delayed diagnosis of Turner syndrome: a single Centre UK study. Int J Pediatr Endocrinol 2018;2018:4. Epub 2018 Jun 26

6. Kirk SA. Educating Exceptional Children. Children with physical disabilities and health impairments, (10th ed). Boston: H. Mifflin Company College Division, 2002:492-534.

7. Gravholt CH, Andersen NH, Conway GS, Dekkers OM, Geffner ME, Klein KO, Lin AE, Mauras N, Quigley CA, Rubin K, Sandberg DE, Sas TCJ, Silberbach M, Söderström-Anttila V, Stochholm K, van Alfen-van derVelden JA, Woelfle J, Backeljauw PF; International Turner Syndrome Consensus Group. Clinical practice guidelines for the care of girls and women with Turner syndrome: proceedings from the 2016 Cincinnati International Turner Syndrome Meeting. Eur J Endocrinol 2017;177:170.

8. Bondy CA; Turner Syndrome Study Group. Care of girls and women with Turner syndrome: a guideline of the Turner Syndrome Study Group. J Clin Endocrinol Metab 2007;92:10-25. Epub 2006 Oct 17

9. Leech N, Barrett K, Morgan GA. SPSS for intermediate statistics: Use and interpretation: Routledge; 2013

10. Lippe B. Turner syndrome. Endocrinol Metab Clin North Am 1991;20:121-152.

11. Nielsen J, Wohlert M. Chromosome abnormalities found among 34,910 newborn children: results from a 13-year incidence study in Arhus, Denmark. Hum Genet 1991;87:81-83.

12. Yeşilkaya E, Bereket A, Darendeliler F, Baş F, Poyrazoğlu Ş, Küçükemre Aydın B, Darcan Ş, Dündar B, Büyükinan M, Kara C, Sarı E, Adal E, Akıncı A, Atabek ME, Demirel F, Çelik N, Özkan B, Özhan B, Orbak Z, Ersoy B, Doğan M, Ataş A, Turan S, Gökşen D, Tarım Ö, Yüksel B, Ercan O, Hatun Ş, Şimşek E, Ökten A, Abacı A, Döneray H, Özbek MN, Keskin M, Önal H, Akyürek N, Bulan K, Tepe D, Emeksiz HC, Demir K, Kızılay D, Topaloğlu AK, Eren E, Özen S, Abalı S, Akın L, Selver Eklioğlu B, Kaba S, Anık A, Baş S, Ünüvar T, Sağlam H, Bolu S, Özgen T, Doğan D, Deniz Çakır E, Şen Y, Andıran N, Çizmecioğlu F, Evliyaoğlu O, Karagüzel G, Pirgon Ö, Çatlı G, Can HD, Gürbüz F, Binay Ç, Baș VN, Fidancı K, Polat A, Gül D, Açıkel C, Demirbilek H, Cinaz P, Bondy $\mathrm{C}$. Turner syndrome and associated problems in Turkish children: a multicenter study. J Clin Res Pediatr Endocrinol 2015;7:27-36.

13. Lee MC, Conway GS. Turner's syndrome: challenges of late diagnosis. Lancet Diabetes Endocrinol 2014;2:333-338. Epub 2013 Dec 6

14. Kringos DS. The importance of measuring and improving the strength of primary care in Europe: results of an international comparative study. Turkish Journal of Family Practice 2013;17:165-179.

15. Ranke MB, Saenger P. Turner's syndrome. Lancet 2001;358:309-314.

16. Gould HN, Bakalov VK, Tankersley C, Bondy CA. High levels of education and employment among women with Turner syndrome. J Women's Health (Larchmt) 2013;22:230-235. Epub 2013 Feb 19

17. Bryman I, Sylven L, Berntorp K, Innala E, Bergstrom I, Hanson C, Oxholm M, Landin-Wilhelmsen K. Pregnancy rate and outcome in Swedish women with Turner syndrome. Fertil Steril 2011;95:25072510. Epub 2011 Jan 22

18. Landin-Wilhelmsen K, Bryman I, Wilhelmsen L. Cardiac malformations and hypertension, but not metabolic risk factors, are common in Turner syndrome. J Clin Endocrinol Metab 2001;86:4166-4170.

19. Kim HK, Gottliebson W, Hor K, Backeljauw P, Gutmark-Little I, Salisbury SR, Racadio JM, Helton-Skally K, Fleck R. Cardiovascular anomalies in Turner syndrome: spectrum, prevalence, and cardiac MRI findings in a pediatric and young adult population. AJR Am J Roentgenol $2011 ; 196: 454-460$.

20. Dawson-Falk KL, Wright AM, Bakker B, Pitlick PT, Wilson DM, Rosenfeld RG. Cardiovascular evaluation in Turner syndrome: utility of MR imaging. Australas Radiol 1992;36:204-209.

21. Callery P, Smith L. A study of role negotiation between nurses and the parents of hospitalized children. J Adv Nurs 1991;16:772-781.

22. Merkens MJ, Perrin EC, Perrin JM, Gerrity PS. The awareness of primary physicians of the psychosocial adjustment of children with a chronic illness. J Dev Behav Pediatr 1989;10:1-6. 
Supplementary 1. The questionnaire for physicians about Turner syndrome

Please select the right option according to you

\section{Descriptive information}

1. Your branch?
a. Pediatrician
b. Gynecologists
C. Family physicians

2. How would you describe your level of knowledge about Turner syndrome?
a. Adequate
b. Insufficient
c. No idea

3. How many years have you practiced in your profession?
a. $<1$ year
b. $1-5$ years
C. 5-10 years
d. Over 10 years

4. What is the type of institution you work with?
a. University hospital
b. Training and research hospital
c. State hospital
d. Primary care clinics

\section{Knowledge questions}

5. What is the frequency of Turner's syndrome?
a. $1 / 1500-1 / 2500$
b. $1 / 10,000-1 / 15,000$
C. $1 / 100,000$
d. $1 / 1000,000$

6. In which sex type is Turner syndrome seen?
a. Women
b. Men
c. In both

7. What is the chromosomal anomaly in Turner's syndrome?
a. 22 q11 deletion
b. $45 \mathrm{XO}$
c. $45 \mathrm{XXY}$
d. PTPN11 gene mutation

8. Which of the following is true in Turner syndrome?
a. Hypogonadotropic hypogonadism
b. Normogonadotropic hypogonadism
c. Hypergonadotropic hypogonadism

9. Which of the following is not a physical characteristic of Turner syndrome?
a. Cubitus valgus
b. High-arch palate
c. Syndactyly
d. Edema of the hands and feet in the infant

10. What is the most common finding in Turner syndrome?
a. Webbed neck
b. Widely spaced nipples
c. Short stature
d. Madelung deformity

11. What is the most common cardiovascular disease seen in Turner syndrome?
a. Ventricular septal defect
b. Hypoplastic left heart syndrome
c. Bicuspid aortic valve
d. Atrial septal defect

12. Which of the following is false regarding fertility in patients with Turner syndrome?

a. Spontaneous pregnancy can be achieved in most patients.

b. $99 \%$ of patients are infertile.

c. In the case of pregnancy, the risk of aortic dissection and/or rupture is high.

d. Oocyte cryopreservation should be performed before the first sign of puberty. 
13. Which of the following is true about the intelligence of children with Turner syndrome?
a. General intelligence can be slightly delayed compared to the normal population.
b. There is serious mental retardation.
c. Intelligence is normal.

14. Which of the following statements is correct?

a. There is a lower risk of malignancy than in the normal population.

b. In patients with Y chromosome or Y chromosome fragmentation, prophylactic gonadectomy should be performed due to the risk of gonadal tumor.

c. The risk of endometrial cancer decreases in patients receiving estrogen therapy.

d. The incidence of multiple melanocytic nevi is lower than in the general population.

15. Which of the following is wrong related to Turner syndrome and osteoporosis?

a. The risk of osteoporosis is increased in Turner syndrome patients.

b. After 18 years of age, bone density should be measured.

c. Estrogen treatment increases bone mass.

d. Patients should be prohibited from exercising.
16. Which of the following is the definitive diagnosis of Turner syndrome?
a. Pelvic ultrasonography
b. Karyotype analysis
C. Clinical findings
d. Growth hormone stimulation test

17. Which of the following is associated with $S H O X$ gene mutation in Turner syndrome?
a. Delayed puberty
b. Short stature
c. Germ cell defect
d. Streak gonad

18. Which of the following is false about treatment in Turner syndrome?

a. It is possible for patients to reach adult height with growth hormone treatment.

b. Induction and continuity of puberty is provided by estrogen treatment.

c. Growth hormone and estrogen treatment increases bone mass.

d. Estrogen therapy has no effect on stature. 
Supplementary 2. The Turner syndrome questionnaire for the parents

Please select the right option according to you.

Age/Gender:

Education status: a. Primary school, b. High schooluniversity

\section{Knowledge questions}

1. Turner syndrome is a genetic disease.
a) Yes
b) No

2. Turner syndrome is only seen in girls.
a) Yes
b) No

3. Turner syndrome can be diagnosed during pregnancy.
a) Yes
b) No

4. The most important finding of Turner syndrome is short stature.
a) Yes
b) No

5. In Turner syndrome, sex chromosomes are normal in number and structure.
a) Yes
b) No

6. Children with Turner syndrome are unlikely to have children.
a) Yes
b) No

7. In Turner syndrome, the intelligence levels of children are low.
a) Yes
b) No

8. In Turner syndrome, congenital heart diseases can be seen.
a) Yes
b) No

9. There is no definitive treatment for Turner syndrome.
a) Yes
b) No

10. In Turner syndrome, short stature can be treated with growth hormone replacement.
a) Yes
b) No

11. In Turner syndrome, some cancers are more common than in normal populations.
a) Yes
b) No

12. Diabetes mellitus, thyroid and celiac diseases are more common in patients with Turner syndrome.
a) Yes
b) No

13. Growth hormone treatment in Turner syndrome is effective in preventing infertility.
a) Yes
b) No

14. Estrogen treatment in Turner syndrome prevents osteoporosis.
a) Yes
b) No

15. Children with Turner syndrome should be examined for renal diseases.
a) Yes
b) No

16. Patients with Turner syndrome should receive psychiatric support.
a) Yes
b) No

17. Patients with Turner syndrome do not need to be under medical supervision in adulthood.
a) Yes
b) No 